M. M. Zanone $\cdot$ E. Favaro $\cdot$ S. Doublier •

B. Lozanoska-Ochser $\cdot$ M. C. Deregibus $\cdot$ J. Greening •

G. C. Huang • N. Klein · P. Cavallo Perin •

M. Peakman - G. Camussi

\title{
Expression of nephrin by human pancreatic islet endothelial cells
}

Received: 8 September 2004 / Accepted: 18 April 2005 / Published online: 12 July 2005

(C) Springer-Verlag 2005

\begin{abstract}
Aims/hypothesis: The islet microcirculation has morphological characteristics resembling those of renal glomeruli. Transcription of the nephrin gene, a highly specific barrier protein of the slit diaphragm of podocyte foot processes, has been reported in the pancreas, although its cellular localisation and function remain to be defined. In this study, we purified and characterised microvascular endothelial cells (MECs) isolated from human islets and investigated the expression and distribution of nephrin on these cells. Methods: Human islet MECs were extracted and purified using anti-CD105-coated immunomagnetic beads and their endothelial characteristics were confirmed by expression of classical endothelial markers and basal high-level expression of intercellular adhesion molecule-1 and TNF- $\alpha$-inducible vascular cell adhesion molecule- 1 . Nephrin expression was assessed by immunofluorescence, flow cytometric analysis and western blotting on cell lysates, as well as by RT-PCR. Results: Immunofluorescence studies detected nephrin in a fine, punctate, diffuse pattern on cultured islet MECs, and also in human pancreatic islet sections. In both cases nephrin colocalised with endothelial markers. TNF- $\alpha$ treatment induced a marked reduction and redistribution of the protein in one or multiple aggregates. Nephrin expression was confirmed by
\end{abstract}

M. M. Zanone $(\bowtie) \cdot$ E. Favaro · S. Doublier · M. C. Deregibus · P. Cavallo Perin · G. Camussi

Department of Internal Medicine and Centre of Experimental Medicine (CeRMS), University of Torino,

Corso Dogliotti 14,

Torino, Italy

e-mail: mmz@libero.it

Tel.: +39-011-6336708

Fax: +39-011-6631184

B. Lozanoska-Ochser · J. Greening · G. C. Huang · M. Peakman Departments of Immunobiology and Diabetes and Internal Medicine, Guy's, King's and St Thomas's School of Medicine, London, UK

N. Klein

Department of Immunobiology,

Institute of Child Health,

London, UK flow cytometry, western blotting and RT-PCR studies. In contrast, nephrin could not be detected at the protein or mRNA level in human macro- and microvascular cells from other sites. Conclusions/interpretation: Nephrin is expressed at protein and mRNA levels in islet microendothelium, supporting the hypothesis that islet MECs exhibit distinctive morphological characteristics that indicate functional specialisation of potential pathophysiological importance.

Keywords Adhesion molecules · Endothelial cells · Islets of Langerhans · Nephrin

Abbreviations ECAF: endothelial cell attachment factor ECGF: endothelial cell growth factor - EGF: epidermal growth factor - FITC: fluorescein isothiocyanate - GAPDH: glyceraldehyde-phosphate dehydrogenase - HMEC-1: human dermal-derived microvascular endothelial cells . ICAM-1: intercellular adhesion molecule-1 - MEC: microvascular endothelial cell - MCAM: melanoma cell adhesion molecule - MFI: mean fluorescence intensity TEC: tumour microendothelial cell - TRITC: tetramethyl rhodamine - VCAM-1: vascular cell adhesion molecule-1 . VEGF: vascular endothelial cell growth factor . vWF: von Willebrand factor

\section{Introduction}

The microvasculature is a key interface between the blood and tissues and participates in numerous pathophysiological processes. The heterogeneity of microvascular endothelial cells (MECs) derived from different organs [1-6] indicates strongly that these cells have specialised functions at different anatomical sites. Thus by studying the features of tissue-derived endothelium, we might gain considerable insight into the physiological and pathological processes taking place within a specific organ.

In keeping with this phenotypic and functional heterogeneity amongst endothelial cells, the pancreatic islet microcirculation is characterised by a dense network of 
sinusoidal capillaries branching from arterioles entering the islet. Although the fine organisation of the vascular architecture is still being debated [7,8], the capillaries course through the islet in a tortuous fashion, with the alpha, beta, delta and PP cells nestled within this network such that each endocrine cell is in close proximity to an endothelial cell. Importantly, the capillaries have a distinctive fenestrated endothelium, as demonstrated by in vivo $[9,10]$ and in vitro [11] studies. This facilitates a rapid exchange of signalling communication and substance exchange. Pancreatic islets express vascular endothelial cell growth factor (VEGF), which contributes to the formation of these endothelial cell surface fenestrae [11-13]. It is also a characteristic of these cells that they express $\alpha 1$ proteinase inhibitor [11], which is not only an enzyme inhibitor but also a known immune regulator [14, 15].

Given these distinctive structural features, it is likely that intra-islet MECs play a pivotal role in islet physiology and the pathogenesis of type 1 and 2 diabetes. It is known that islet MECs are important in the delivery of oxygen and nutrients to endocrine cells, induce insulin gene expression during islet development [16], and provide secretory signals from other cells mediated through luminal MEC receptors [17]. Importantly, the fenestrated islet microvascular endothelium not only facilitates rapid release of insulin into the circulation, but also appears to play a role in fine-tuning blood glucose sensing and regulation $[12,18-20]$.

The ultrastructural features of islet MECs are highly reminiscent of the appearance of the renal glomerulus. Several recent studies have advanced our understanding of the molecular components of such filtration structures. Notable amongst these components is nephrin, a highly specific barrier protein [21] known to be located in the glomerular slit diaphragm [22, 23], the ultrathin filter membrane formed by podocyte foot processes [24]. Intriguingly, nephrin has also been described in murine pancreas and in isolated human islets $[25,26]$. However, the suggested localisation within beta cells is controversial [27]; the exact protein localisation in the pancreatic islets therefore remains to be clarified. Against this background, we tested the hypothesis that nephrin is expressed in human islet MECs. We therefore set out to obtain, purify and propagate human islet MECs and investigate their expression of this barrier protein.

\section{Materials and methods}

Islet endothelial cell isolation, purification and culture Human islets were obtained from the pancreas of an organ donor using a modification of Ricordi's technique, as described [28]. Islet isolations were carried out in the Cell Isolation Unit at King's College Hospital, and these studies were approved by the local ethical review committee. Approximately 100,000 human islets, $85-90 \%$ pure as assessed by dithizone staining, were incubated at $37^{\circ} \mathrm{C}$ in RPMI (Life Technologies, Paisley, UK) supplemented with collagenase type I-A $(1 \mathrm{mg} / \mathrm{ml}$; Sigma Aldrich, Poole,
Dorset, UK). To remove larger debris, the digest was passed through a $70-\mu \mathrm{m}$ filter, and the remaining cell suspension was washed twice at $300 \mathrm{~g}$ for $10 \mathrm{~min}$ in RPMI $/ 2.5 \%$ fetal calf serum (FCS; Euroclone, Paignton, UK). The resulting cell pellet was resuspended in $0.25 \%$ trypsin/ 1 mmol EDTA (Life Technologies) for $10 \mathrm{~min}$ at $37^{\circ} \mathrm{C}$ to obtain a single-cell suspension, washed and resuspended in $80 \mu \mathrm{l}$ of PBS $/ 0.5 \%$ FCS, with $20 \mu \mathrm{l}$ of anti-CD 105 immunomagnetic beads (Dynal, Wirral, UK). After 15 min at $6^{\circ} \mathrm{C}$, cells were washed, resuspended in appropriate buffer and positively selected using a MP3 magnetic cell particle separator (Dynal), according to the manufacturer's instructions. Finally, the enriched islet MECs were resuspended in MCDB131 medium (Life Technologies) with $20 \% \mathrm{FCS}, 10 \mathrm{mmol}$ L-glutamine, $12 \mu \mathrm{g} / \mathrm{ml} \mathrm{ECGF,} 10 \mathrm{ng} /$ $\mathrm{ml}$ EGF, $1 \mu \mathrm{g} / \mathrm{ml}$ hydrocortisone (all products from Clonetics, San Diego, CA, USA) and antibiotics (100 IU/ml penicillin, $100 \mu \mathrm{g} / \mathrm{ml}$ streptomycin) (Sigma), on to tissue culture plates coated with endothelial cell attachment factor (Sigma). Cells were grown to confluence and analysed for the expression of endothelial cell surface markers. If necessary, the positive immunomagnetic bead selection was repeated to achieve more than $90 \%$ purity of the islet MEC culture.

Cells were grown until confluent, with the medium changed every 48-72 h, washed twice and dispersed with trypsin/EDTA, as required for analysis or subculture (splitting cells $1: 2$ or $1: 3$ ).

Islet MECs were also cultured in complete medium that contained a high glucose concentration $(28 \mathrm{mmol} / \mathrm{l})$ and was changed every $48 \mathrm{~h}$.

As control endothelial cell lines, HUVEC cultures were established as described [29]. In addition, we studied the immortalised HMEC-1 line [30] and a renal tumour microendothelial cell (TEC) line [31], previously described.

Phenotypic characterisation and detection of endothelial cell surface molecules From the earliest passages for which sufficient cells were available for study, endothelial phenotype was assessed by flow cytometric analysis of the cell surface phenotype, staining for basal expression of endothelial markers and adhesion molecules, or of permeabilised cells for intracellular von Willebrand factor (vWF) staining, as described [32]. The following antibodies were used: anti-human monoclonal antibody against CD105-R-phycoerythrin (undiluted; Serotec, Oxford, UK), CD146-fluorescein isothiocyanate (FITC) (clone P1H12, final dilution 1:100) (Chemicon, Temecula, CA, USA), E-selectin (CD62E, final dilution 1:100), intercellular adhesion molecule-1 (ICAM-1) (CD54, 1:10), CD106 (vascular cell adhesion molecule-1 [VCAM-1], 1:20) (all from Serotec), rabbit anti-human vWF antiserum (1:200) (Sigma) and R-phycoerythrin-conjugated F $\left(a b^{\prime}\right)_{2}$ fragment of goat anti-mouse immunoglobulins or R-phycoerythrin-conjugated anti-rabbit immunoglobulins (Dako, Glostrup, Denmark). Ten thousand events were collected and results were expressed as mean fluorescence intensity (MFI) and percentage of positive gated events, with gates established using appropriate isotype 
control antibodies. For the adhesion molecules, expression is presented as the mean of five separate flow cytometric analyses. Expression of E-selectin, ICAM-1 and VCAM-1 was also reanalysed after incubation with recombinant human TNF- $\alpha 10 \mathrm{ng} / \mathrm{ml}$ (Sigma) for $4 \mathrm{~h}$. In all experiments, cells were also stained with the corresponding isotype control antibodies and non-specific staining was subtracted from the appropriate population.

Scanning electron microscopy For scanning microscopy, the cells were seeded on gelatin-coated eight-well chamber slides (Nalge Nunc International, Rochester, NY, USA) (approximately $10^{4}$ cells) and cultured for $24-48 \mathrm{~h}$ to subconfluence. Cells untreated or treated with TNF- $\alpha$ $(10 \mathrm{ng} / \mathrm{ml})$ for $1 \mathrm{~h}$ were fixed in Karnovsky's fixative for $1 \mathrm{~h}$, dehydrated in alcohol, dried and coated with gold by sputter-coating (Emitech, Ashford, UK), and examined in a scanning electron microscope (JSM T300; Jeol, Tokyo, Japan) operating at $25 \mathrm{kV}$.

Detection of nephrin expression by immunofluorescence, immunogold labelling, and flow cytometric studies Immunofluorescence on cultured islet MECs was performed as previously described [33]. For intracellular staining, cells were permeabilised by using $1 \%$ paraformaldehyde, $0.5 \%$ Triton X-100 for $10 \mathrm{~min}$.

After washing with PBS $(0.25 \%$ BSA), cells were incubated with anti-nephrin monoclonal antibody $(10 \mu \mathrm{g} / \mathrm{ml})$ (IgG1 48E11, directed against an extracellular domain) [34] or with guinea-pig anti-nephrin polyclonal antibody (diluted 1:50) directed against extracellular (GP-N1), or intracellular (GP-N2) domains (Progen Biotechnik, Heidelberg, Germany) overnight at $4^{\circ} \mathrm{C}$. Cells were washed and subsequently incubated with FITC-conjugated antimouse (Dako) or FITC-conjugated anti-guinea-pig (Sigma) $\mathrm{IgG}$ for $1 \mathrm{~h}$ at room temperature. After washing, the slides were mounted in Vectashield H-1000 mounting medium (Vector Laboratories, Burlingame, CA, USA) and examined by ultraviolet microscopy and digital imaging (Windows MicroImage, version 3.4; Casti Imaging, Venice, Italy) obtained using a low-light video camera (Leica DC100). Immunofluorescence analysis was also performed after incubation of the cells with TNF- $\alpha(10 \mathrm{ng} / \mathrm{ml})$ at room temperature for $1 \mathrm{~h}$. Control experiments included incubation with non-immune isotypic control antibodies or the omission of primary antibody. For comparative experiments, HUVEC, HMEC-1 and renal TECs were stained as described. Immortalised podocytes were used as positive control [35].

Cells were also permeabilised and double-stained for insulin, using rabbit anti-human insulin antibody (1:20) (Santa Cruz Biotechnology, Santa Cruz, CA, USA) and for vWF, using rabbit anti-human vWF antibody $(1: 100)$ for $1 \mathrm{~h}$, followed by tetramethyl rhodamine (TRITC)-conjugated anti-rabbit IgG (Sigma).

Immunofluorescence studies were also performed on sections of cryopreserved pancreas tissue obtained from deceased organ donors. Pancreatic tail samples were snapfrozen, embedded in OCT (Sakura Finetek, Zoeterwoude,
Netherlands) in liquid nitrogen and cryopreserved until use. Three donors were used. Cryostat sections $(5 \mu \mathrm{m})$ were fixed in $3.5 \%$ paraformaldehyde for $15 \mathrm{~min}$ and washed. Sections were incubated with anti-nephrin monoclonal antibody $(10 \mu \mathrm{g} / \mathrm{ml})$ or with guinea-pig anti-nephrin polyclonal GP-N2 antibody (1:50) for $2 \mathrm{~h}$ at room temperature, washed, and incubated with FITC-conjugated anti-mouse or anti-guinea-pig IgG. Sections of normal kidney obtained from nephrectomy were used as a positive control. For colocalisation studies, sections were subsequently double-stained with anti-human insulin antibody or anti-vWF antibody for $1 \mathrm{~h}$, followed by TRITC-conjugated anti-rabbit IgG. Images acquired by examining the sections under a $580 \mathrm{~nm}$ (for TRITC) and $517 \mathrm{~nm}$ (for FITC) narrow bandpass filter were then analysed using digital image analysis.

Immunogold scanning electron microscopy labelling studies were performed on $2.5 \%$ paraformaldehyde-fixed islet MECs using two monoclonal antibodies (IgG1 48E11 or 41F2, [34]) and, as secondary antibody, a 5-nm goldconjugated anti-mouse antibody (BBInternational, Cardiff, UK) followed by silver enhancement (Silver Enhancing Kit; BBInternational). Samples were postfixed in $2.5 \%$ glutaraldehyde, treated, and examined by scanning electron microscopy, as described above.

For flow cytometric analyses, islet MECs were collected with non-enzymatic cell dissociation solution, fixed with $1 \%$ paraformaldehyde for $5 \mathrm{~min}$ and stained for $1 \mathrm{~h}$ at $4{ }^{\circ} \mathrm{C}$ with anti-nephrin monoclonal antibody (final dilution 1:50) (IgG1 48E11) or corresponding isotype antibody, washed and incubated with FITC-conjugated anti-mouse IgG for $1 \mathrm{~h}$ at $4^{\circ} \mathrm{C}$. Comparative studies on the other endothelial cells and podocytes were also performed. In a two-parameter flow cytometric analysis, after staining for nephrin, cells were permeabilised and then stained for vWF, using FITC and R-phycoerythrin respectively as fluorochromes, as described above.

Detection of nephrin expression by western blot analysis Islet MECs cultured in physiological or high glucose concentrations were lysed at $4^{\circ} \mathrm{C}$ for $1 \mathrm{~h}$ in lysis buffer [33] containing $20 \mathrm{mmol}$ CHAPS (3-[(3-cholamidopropyl)-dimethylammonio]-1-propanesulphonate; Sigma). After centrifugation of the lysates at $15,000 \mathrm{~g}$, samples were normalised to $50 \mu \mathrm{g} / \mathrm{sample}$ in $20 \mu \mathrm{l}$ and resolved by $8 \%$ SDS-PAGE under reducing conditions and transferred to nitrocellulose [33]. Membranes were blocked and incubated with a mix of three anti-nephrin monoclonal antibodies (IgG2b 50A9, IgG1 47B8, IgG1 41F2) [34] at a concentration of $2.5 \mu \mathrm{g} / \mathrm{ml}$, or with GP-N2 polyclonal antibody $(1: 500)$ overnight at $4{ }^{\circ} \mathrm{C}$. Blots were probed with peroxidase-conjugated goat anti-mouse $\operatorname{IgG}\left(\begin{array}{lll}1: 50 & 000\end{array}\right)$ (Pierce, Rockford, IL, USA) or protein A (Amersham, Little Chalfont, UK) for $1 \mathrm{~h}$ at room temperature and developed with chemiluminescence reagents (ECL; Amersham). Immortalised podocytes, HUVEC and HMEC-1 served as control cells.

For reprobing, nitrocellulose filters were first stripped of antibody as described [33], and subsequently incubated as 
above with anti-nephrin monoclonal antibody preadsorbed on podocytes in culture for $12 \mathrm{~h}$.

Semiquantitative RT-PCR analysis of nephrin expression RT-PCR was performed using total RNA from islet MECs, immortalised podocytes and HMEC-1, extracted and reverse-transcribed as previously described [33]. Fixed amounts of cDNA $(5 \mu \mathrm{l}$ for the nephrin gene and $2 \mu \mathrm{l}$ from 1:10 dilution for the glyceraldehyde-phosphate dehydrogenase $[G A P D H]$ gene, used as a housekeeping gene) were used directly for individual PCR amplifications. Sequence-specific oligonucleotide primers (TIB Molbiol, Genova, Italy) were designed (h-nephrin: 5' reverse TgT ACA TgT gAA gAg ggC gTA A; 5' forward ggA CAT AgT CTg CAC TgT CgA T; h-GAPDH [33]). Times and temperature for denaturation, annealing and extension were $30 \mathrm{~s}$ at $94^{\circ} \mathrm{C}$, $30 \mathrm{~s}$ at $55^{\circ} \mathrm{C}$ and $45 \mathrm{~s}$ at $72^{\circ} \mathrm{C}$, respectively. Amplification products for h-nephrin (492 bp) and h-GAPDH (598 bp) were visualised by ethidium bromide staining after agarose gel electrophoresis.

\section{Results}

Islet endothelial cell phenotype and surface molecule expression As shown in Fig. 1a, isolated islet MECs exhibited an elongated shape without typical cobblestone- like endothelial cell morphology and maintained endothelial cell characteristics, as assessed by detection of vWF expression and endothelial-cell-associated epitopes, i.e. the transmembrane glycoprotein melanoma cell adhesion molecule (MCAM) (CD146) and endoglin (CD105) by FACS analysis (Fig. 1b-d).

By cytofluorimetric analysis, islet MECs showed high basal expression of ICAM-1 (CD54) (mean \pm SD MFI 57.2 \pm 33 , mean \pm SD percentage of positive cells $69.7 \pm 14$ ), and no detectable basal expression of VCAM-1 (CD106) and E-selectin (CD62E) (Fig. 1e,f). TNF- $\alpha$ treatment induced neo-expression of VCAM-1 (MFI 28 \pm 6 , percentage of positive cells $51.6 \pm 12$ ).

Islet MECs grown under high-glucose conditions assumed a more rounded shape, with progressive cell shrinkage and detachment. After 1 week of culture, the number of islet MECs was reduced to $20.3 \pm 14.2 \%(n=5)$ of that in a physiological concentration of glucose.

By scanning electron microscopy, islet MECs appeared flat with a rather smooth surface, and with nuclei and nucleoli protruding from the even surface. Several fenestrations were detectable (Fig. 2a). TNF- $\alpha$ treatment gave rise to marked cell retraction, ruffling of the surface, and loss of reciprocal contacts (Fig. 2b). Nuclei and nucleoli were no longer visible due to the thickening of the cell bodies, as a consequence of the retraction of peripheral cytoplasmic laminae. a

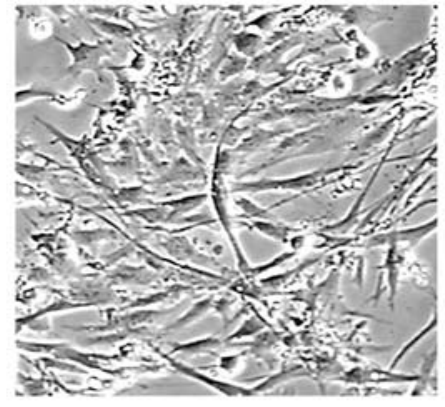

\section{d}

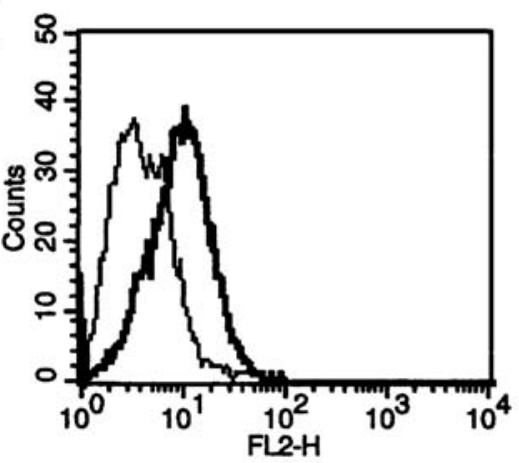

b

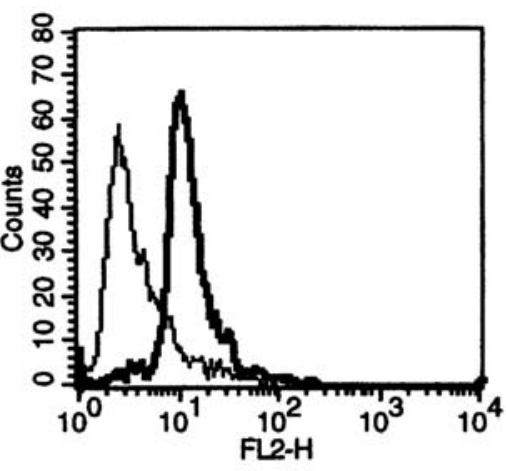

e

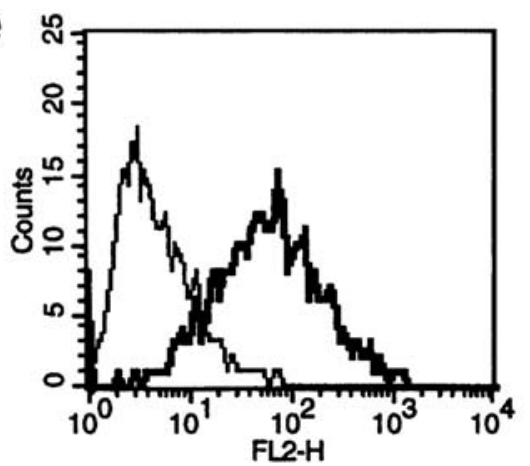

C

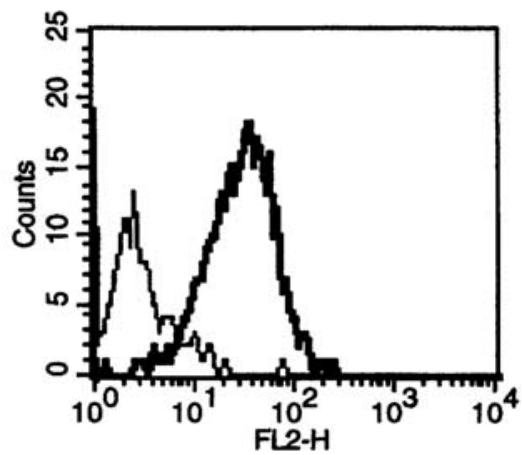

f

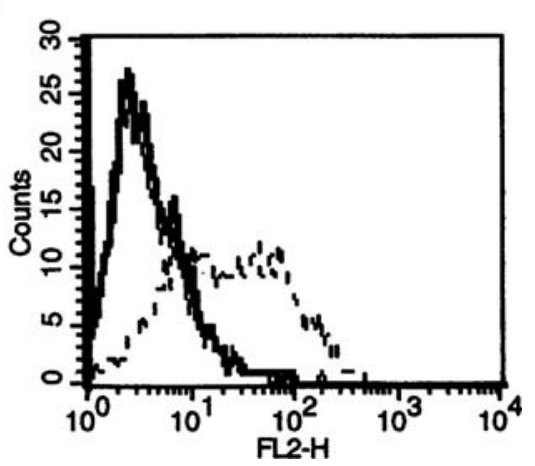

Fig. 1 Representative morphological and flow cytometric analysis of primary islet MECs. a Light microscopy of cultured islet MEC observed by phase contrast (original magnification $\times 200$ ). b-e Cytofluorimetric detection of staining for $\mathrm{vWF}$ (b), endoglin (CD105) (c), the transmembrane glycoprotein MCAM (CD146) (d) and ICAM-1 (e). f VCAM-1 expression after treatment (dashed line) or not (solid line) with TNF- $\alpha(10 \mathrm{ng} / \mathrm{ml})$ for $4 \mathrm{~h}$. The thin lines represent the corresponding isotype control antibodies. Three to five experiments were performed with similar results 

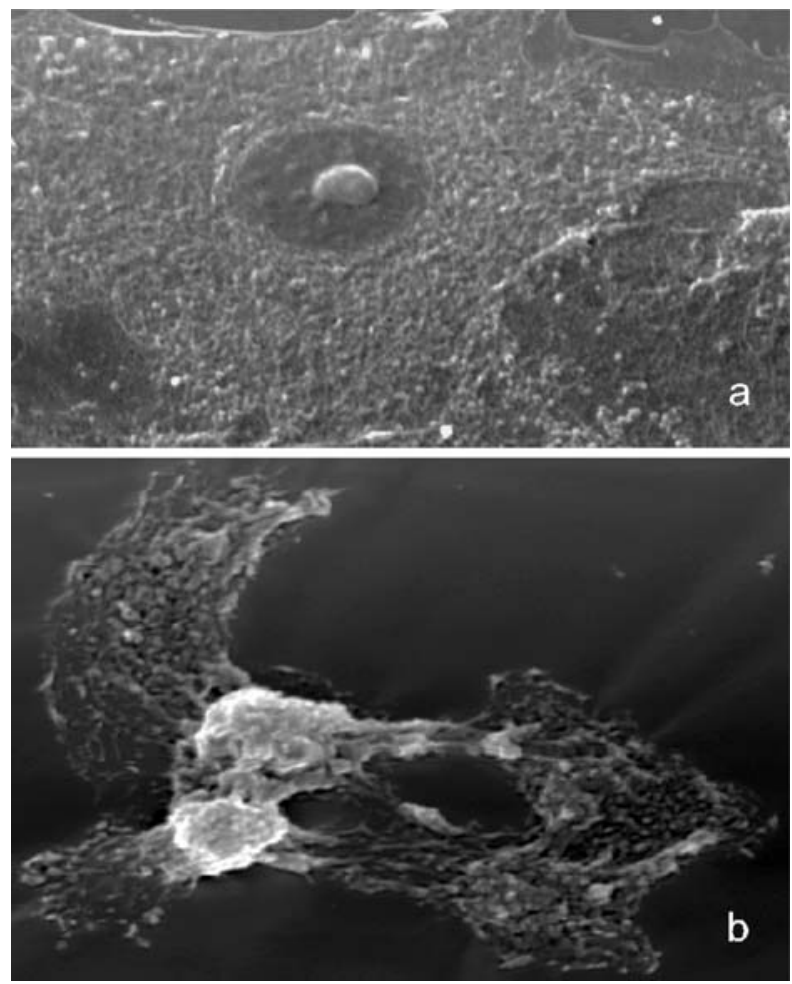

Fig. 2 Representative micrographs of scanning electron microscopy of islet MECs untreated (a) or treated (b) with TNF- $\alpha(10 \mathrm{ng} / \mathrm{ml})$ for $1 \mathrm{~h}$. TNF- $\alpha$ treatment induced marked retraction of the cells, ruffling of the surface and loss of reciprocal contacts; nuclei and nucleoli were no longer visible (original magnification $\times 1,500$ )
Nephrin expression in islet endothelial cells and pancreatic islets The immunogold labelling showed nephrin localisation on the surface of islet MECs, without accumulation at the cell-to-cell junctions, at variance with the distribution observed in podocytes (Fig. 3a). Indirect immunofluorescence studies detected the expression of nephrin in permeabilised cells stained with antibody directed against the intracellular domain (Fig. 3b), and in a fine, punctate, diffuse pattern on non-permeabilised islet MECs stained with monoclonal antibody and polyclonal antibody against extracellular domains (Fig. 3c). When the cells were incubated with TNF- $\alpha$ for $1 \mathrm{~h}$, nephrin appeared focally redistributed in one or multiple aggregates (capping), leaving parts of the cell surface devoid of antigen (Fig. 3d). Double-staining immunofluorescence studies confirmed that islet MECs did not express insulin (data not shown), but were positive for nephrin and vWF expression (Fig. 4a).

Expression of nephrin on islet MECs was confirmed by flow cytometric analysis (Fig. 4b). In the two-parameter analysis, all islet MECs expressing nephrin were simultaneously positive for the endothelial marker vWF (Fig. 4c), unequivocally proving their endothelial phenotype. The isotypic-negative control, as well as HUVEC, HMEC-1 and TECs, stained negatively with anti-nephrin antibodies in immunofluorescence and flow cytometric studies (Fig. 4d,e).

Culture in a high glucose concentration did not affect the expression of nephrin, which was detected in a pattern similar to that of islet MECs grown in physiological
Fig. 3 Representative immunogold labelling and immunofluorescence micrographs of islet MECs stained with anti-nephrin antibodies. By immunogold staining, nephrin appears distributed on the surface of islet MECs, without accumulation at cell-to-cell junctions (a) (original magnification $\times 1,000$ ). Using immunofluorescence, nephrin is detectable on the cell surface in a fine, punctate, diffuse pattern, both by antibody directed against the intracellular domain of nephrin in permeabilised cells (b) and by antibody against the extracellular domain in non-permeabilised cells (c). d When the cells were incubated with TNF- $\alpha(10 \mathrm{ng} / \mathrm{ml})$ for $1 \mathrm{~h}$, nephrin appeared focally redistributed in one or multiple aggregates (capping, arrows), leaving parts of the cell surface devoid of antigen. Original magnification: $\times 250($ b $), \times 400$ $(\mathbf{c}, \mathbf{d})$. Five experiments were performed with similar results
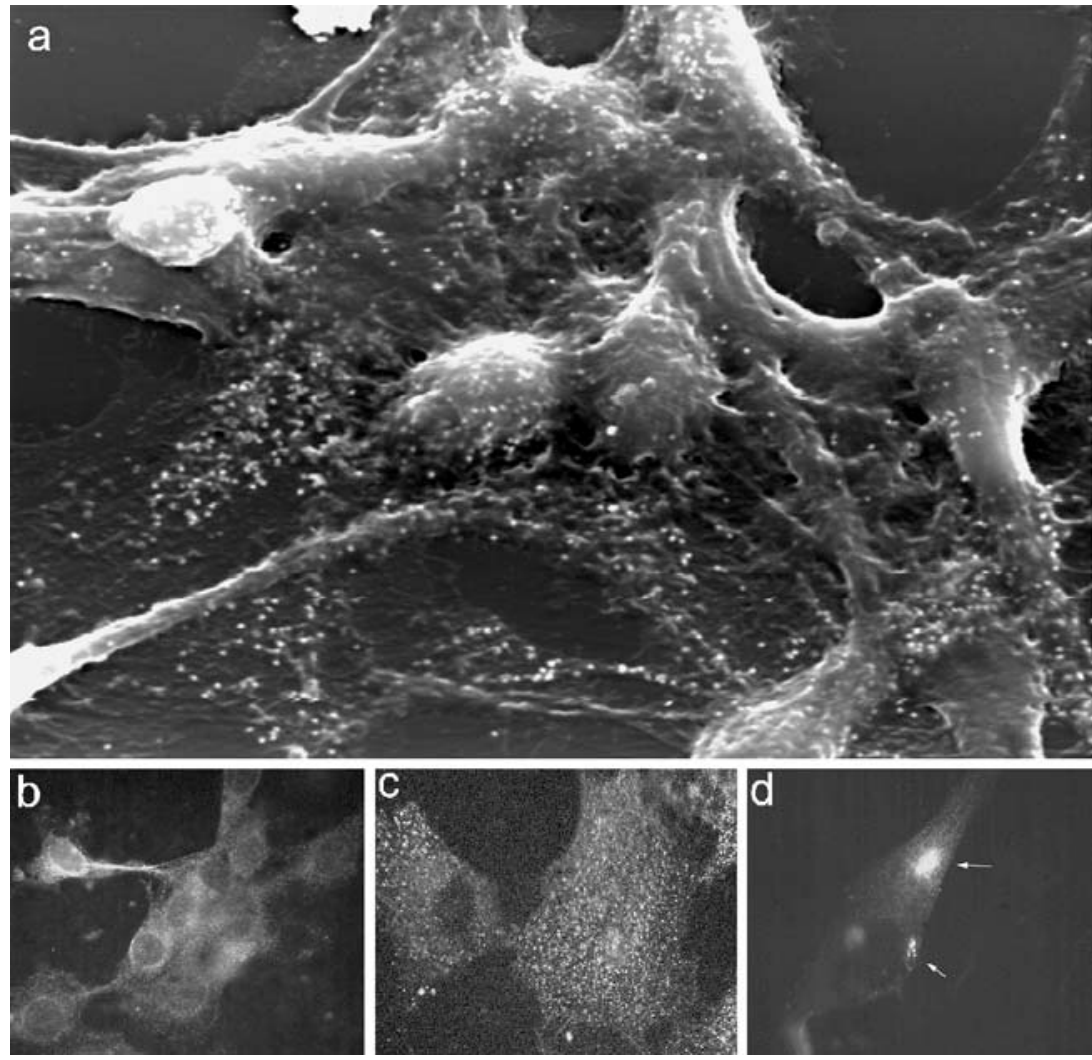
Fig. 4 Representative immunofluorescence micrographs and flow cytometric analysis of islet MECs. a Double staining for nephrin and vWF shows the localisation of these two antigens in the same cells (original magnification $\times 400$ ). Using flow cytometry, up to $81 \%$ of islet MECs were positive for nephrin (b) and nephrin was expressed only in cells positive for the endothelial marker vWF, represented as signals in the upper right-hand quadrant (c). Representative negative flow cytometry of HMEC-1 (d), which are only positive for $\mathrm{VWF}$ and are represented in the upper left-hand quadrant (e). Thin lines represent the corresponding isotype control antibody
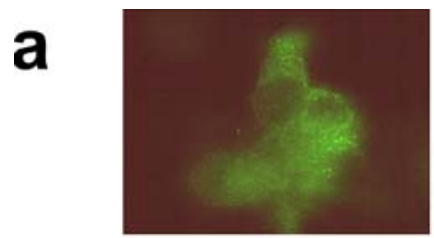

Nephrin
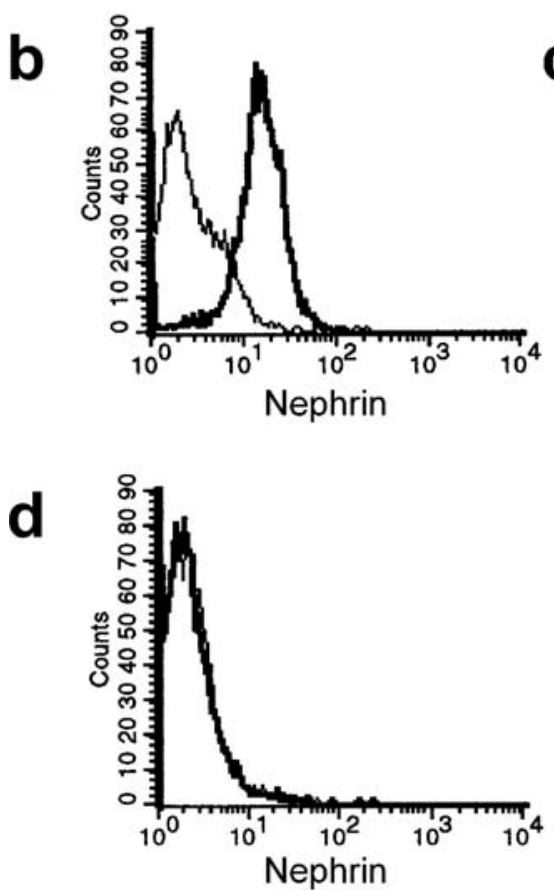

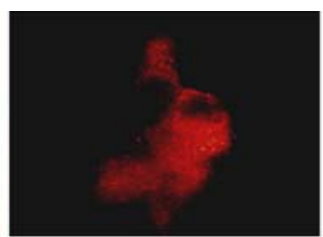

vWF

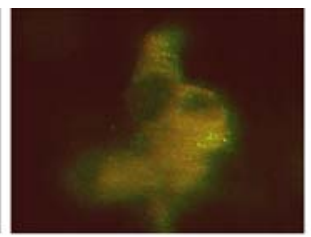

Merge

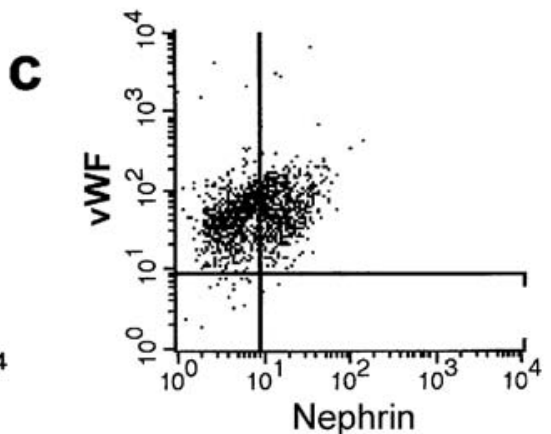

e

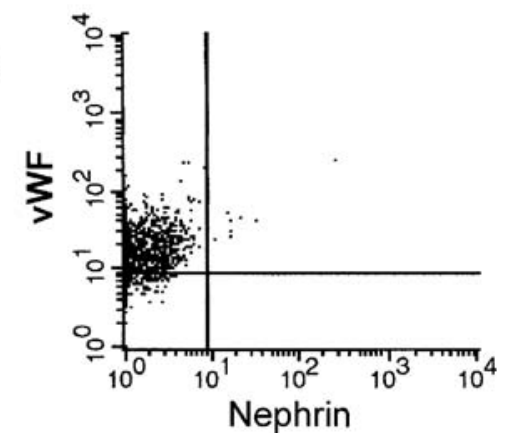

glucose conditions, after both $72 \mathrm{~h}$ and 8 days of culture (data not shown).

Immunofluorescence studies on sections of human pancreas detected nephrin expression within islets, non-colocalising in double immunofluorescence, with insulin-positive cells (Fig. 5a-c). The pattern was reminiscent of the distribution of fine vessels penetrating the islets, confirmed in double immunofluorescence using antibody for vWF (inset in Fig. 5c).
Western blot and RT-PCR analyses Primary islet MECs showed expression of nephrin in western blot analysis using either monoclonal antibodies directed against extracellular domains or polyclonal antibodies directed against intracellular domain GP-N2, as a band of approximately $160 \mathrm{kDa}$ (Fig. 6a). Immortalised podocytes, used as a positive control, showed expression of the protein with a higher molecular mass $(180 \mathrm{kDa})$, as previously shown [35]. Antigen preadsorption of the antibodies completely
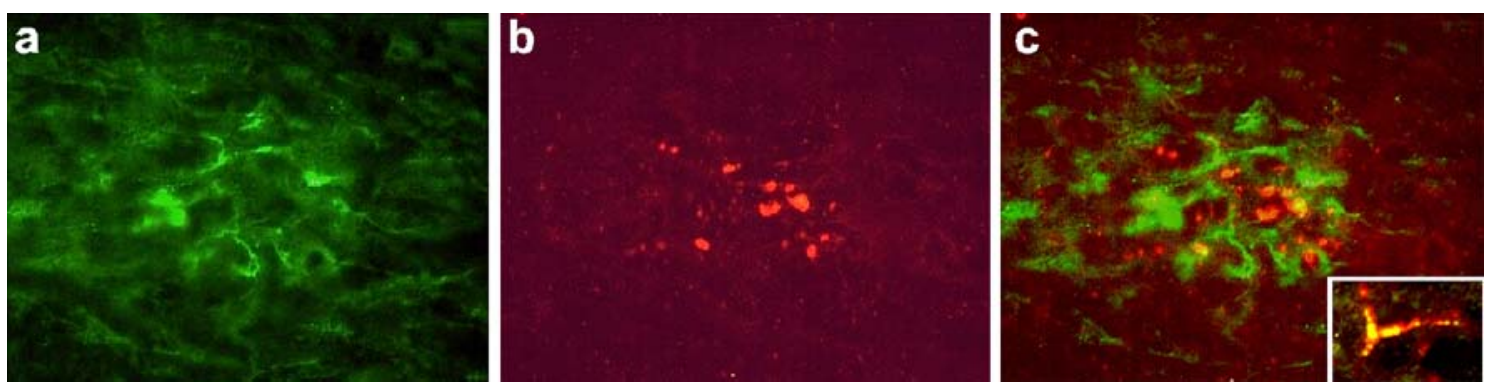

Fig. 5 Representative immunofluorescence micrographs of pancreatic islets stained with anti-nephrin monoclonal antibody. Immunofluorescence staining for nephrin (a) (detected with FITC-conjugated secondary antibody) of a pancreatic islet, and insulin (b) detected with TRITC-conjugated antibody (original magnification $\times 400$ ). c The two stainings merged to show the different localisation within the islet. Inset: merged double staining of nephrin and vWF (detected with TRITC-conjugated antibody) in a consecutive section, indicating the association of nephrin with a vessel. Three different pancreas were examined with similar results 


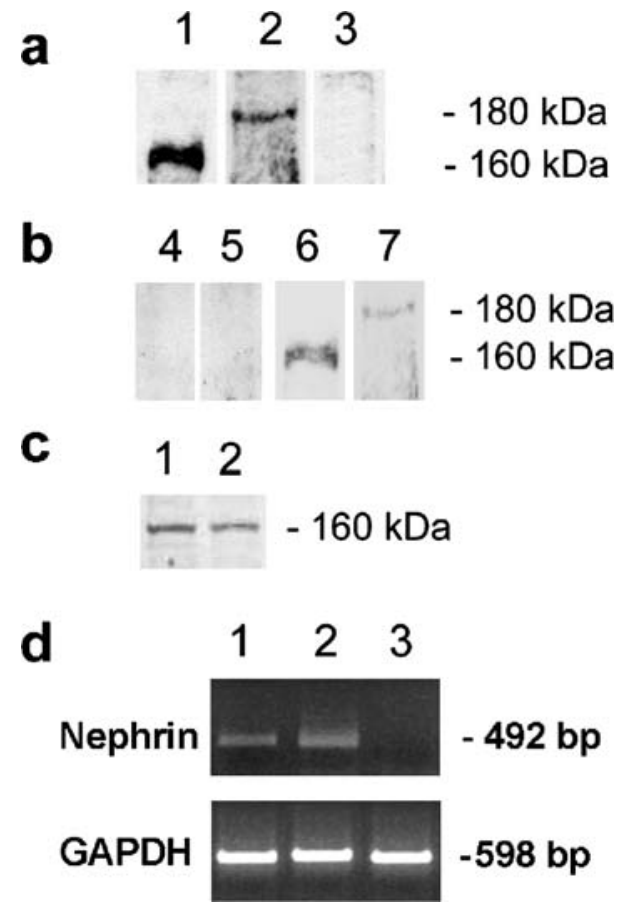

Fig. 6 Representative western blot and RT-PCR analysis of nephrin expression in islet MECs. a Islet MECs (lane 1) and podocyte (lane 2) lysates express nephrin as a band of approximately 160 and $180 \mathrm{kDa}$, respectively. Lane 3 shows western blot analysis of HMEC-1 cell lysates that did not express nephrin. b Preadsorption of anti-nephrin monoclonal antibody with cultured human podocytes completely abolished the immunoreactivity (lane 4, islet MECs; lane 5, podocytes), with reappearance of the band on reprobing the membrane with non-adsorbed antibodies (lane 6, islet MECs; lane 7, podocytes). c No variation in nephrin expression was observed by western blot analysis of lysates of cells cultured in high (lane 1) and physiological (lane 2) glucose concentrations. d Representative agarose gels resolving PCR products after amplification for nephrin detected as a band of $492 \mathrm{bp}$ and for GAPDH in islet MECs (lane 1), immortalised podocytes (lane 2) and HMEC-1 cells (lane 3 ). Three experiments were performed with similar results

abolished the immunoreactivity (Fig. 6b, lanes 4 and 5), with reappearance of the band on further incubation of the membrane with non-adsorbed antibodies (Fig. 6b, lanes 6 and 7).

Culture in a high glucose concentration for up to 8 days again did not reduce the expression of nephrin as shown by western blot analysis (Fig. 6c).

RT-PCR analysis detected nephrin mRNA expression in islet MECs and in podocytes as a band 492 bp (Fig. 6d). No bands were detected by western blotting and RT-PCR when using HUVEC and HMEC-1 cell lysates and mRNA, respectively.

\section{Discussion}

The present work demonstrates for the first time the expression of nephrin at protein and mRNA levels in primary endothelial cells purified and cultured from human pancreatic islets, but not in HUVEC or other microvascular endothelial cell lines. Moreover, the nephrin expressed in islet MECs has functional characteristics that are highly reminiscent of the same protein expressed by podocytes in the renal glomeruli, in that in both cell types treatment with TNF- $\alpha$ acts on the cell cytoskeleton to induce a marked redistribution of nephrin expression.

Nephrin is a cell adhesion transmembrane protein of the immunoglobulin superfamily, expressed by the podocyte slit diaphragm, which has a pivotal role in the regulation of glomerular selective permeability [21-24]. In glomerular capillaries, nephrin is unique to podocytes. In the present study, we identified a form of endothelial expression of this protein, which among the endothelial cell types studied appears to be specific to pancreatic islet MECs. This is consistent with the ultrastructural features of these cells in the islet, which form a microvasculature that is characterised by a glomerulus-like network of fenestrated capillaries [7-10]. Future analysis of the nephrin structurefunction relationship in islet microendothelium will reveal its potential contribution to islet-specific transendothelial diffusion.

The discrepancy of expression in cells of different embryological origin, such as glomerular epithelial and endothelial cells, has no immediate explanation. However, nephrin has also been reported in some parts of the central nervous system in mice [25, 36], again suggesting a diverse, ectodermal, origin.

The biological roles of nephrin in extrarenal sites remain unclear, although it has been speculated, for instance, that in Sertoli cells, which form the blood-testis barrier, nephrin might contribute to this function [37]. The presence of nephrin in human islets of Langerhans was reported recently. In that study, tissue immunofluorescence studies suggested that nephrin is localised within pancreatic islet beta cells [26]. However, a more recent study, using different antibodies, did not confirm expression in human beta cells [27]. The present study, which used different specific antibodies directed against intracellular and extracellular domains in immunofluorescence, as well as cytometric, western blotting and RT-PCR assays, with results confirmed by immunogold labelling, shows unequivocally that cultured islet MECs expressing classical endothelial markers also express nephrin. The molecular mass of the nephrin detected is approximately $160 \mathrm{kDa}$, as previously described for nephrin detected in a total extract of human islets [26]. The apparent molecular mass of nephrin expressed by podocytes is $180 \mathrm{kDa}$. It seems probable, therefore, that the pancreatic isoform is a spliced variant of nephrin, referred to as $\alpha$-nephrin, lacking the exon coding for the transmembrane-spanning domain [38]. Alternatively, the difference in apparent molecular mass between glomerular and pancreatic nephrin may be due to posttranslational modification of the protein (predicted molecular mass $135 \mathrm{kDa}$ ), namely a minor $N$-glycosylation [21, 39]. Speculations on the nature of the structure of islet nephrin are further complicated by recent work in transgenic mice, showing that there are specific elements in the tissue-specific expression of nephrin [36]. Further studies on the regulatory mechanisms of the nephrin gene may help to elucidate its function in extrarenal sites. 
Nephrin appears to be more than simply a structural component of the glomerular ultrafiltration barrier [24]. A consensus view from several recent studies might be that nephrin is an adhesion and signalling molecule, modulating a variety of cellular programmes, including proliferation, differentiation and apoptosis, as well as a determinant of cellular ultrastructure [40-44]. How and when nephrin delivers these signals in islet MECs in vivo remains to be unravelled, as does the identity of any nephrin ligands. Some insight into a possible role for nephrin in islet physiology derives from studies in mice with pancreatic VEGF-A deletion. These mice show loss of fenestration and a thicker endothelial cell body, as well as defective blood glucose levels on glucose tolerance testing. These changes may well involve modifications of nephrin expression, which is downregulated in glomeruli of mice treated with neutralising anti-VEGF antibodies [45]. Other studies support the possibility that the islet microvasculature participates in sensing the environment of the islets [18-20].

In preliminary experiments, high-glucose conditions did not alter nephrin expression or distribution. In cultured podocytes, high glucose has been shown not to decrease nephrin expression, which was instead reduced by glycation end-products and angiotensin [33].

Neither diabetes nor any other form of pancreatic endocrinopathy has been described in patients with congenital nephrotic syndrome of the Finnish type (a disease characterised by mutation of the nephrin gene [21]) who early in life have undergone post-transplant immunosuppressive therapy, interfering with glucose metabolism. Further studies are needed to explore whether nephrin expressed in islet microendothelium has any functional relevance, in terms of permeability regulation or signalling functions, and whether there is any interplay between chronic hyperglycaemia and nephrin expression.

Acknowledgements This work was supported by a grant from Regione Piemonte (Italy), Ricerca Sanitaria Finalizzata 2003, and by Ministero della Università e della Ricerca Scientifica (MURST, Italy; Progetto FIRB no. RBAU013W3J-004). We thank Professor K. Tryggvason for kindly providing us the anti-nephrin antibodies. E. Favaro is supported by FIRB. M. Peakman is a Diabetes UK Senior Clinical Research Fellow. B. Lozanoska-Ochser and J. Greening are supported by Diabetes UK.

\section{References}

1. Kubota Y, Kleinman H, Martin GR, Lawley TJ (1988) Role of laminin and basement in the differentiation of human endothelial cells into capillary-like structures. J Cell Biol 107:15891598

2. Charo IF, Shak S, Karasek MA, Davison P, Goldstein IM (1984) Prostaglandin $\mathrm{I}_{2}$ is not a major metabolite of arachidonic acid in cultured endothelial cells from human foreskin microvessels. J Clin Invest 74:914-919

3. Swerlick RA, Lee KH, Wick TM, Lawley TJ (1992) Human dermal microvascular endothelial cells but not human umbilical vein endothelial cells express CD36 in vivo and in vitro. J Immunol 148:78-83
4. Swerlick RA, Garcia-Gonzalez E, Kubota Y, Xu Y, Lawley TJ (1991) Studies of the modulation of MHC antigen and cell adhesion molecule expression on human dermal microvascular endothelial cells. J Invest Dermatol 97:190-196

5. Fujimoto T, Singer SJ (1988) Immunochemical studies of endothelial cells in vivo: II. Chicken aortic and capillary endothelial cells exhibit different cell-surface distributions of the integrin complex. J Histochem Cytochem 36:1309-1317

6. Lidington EA, Moyes DL, McCormack AM, Rose ML (1999) A comparison of primary endothelial cells and endothelial cell lines for studies of immune interactions. Transpl Immunol 7:239-246

7. Brunicardi FC, Stagner J, Bonner-Weir S et al (1996) Microcirculation of the islets of Langerhans. Long Beach Veterans Administration Regional Medical Education Center Symposium. Diabetes 45:385-392

8. Jansson L, Carlsson PO (2002) Graft vascular function after transplantation of pancreatic islets. Diabetologia 45:749-763

9. Vajkoczy P, Olofsson AM, Lehr HA et al (1995) Histogenesis and ultrastructure of pancreatic islet graft microvasculature. Evidence for graft revascularization by endothelial cells of host origin. Am J Pathol 146:1397-1405

10. Lukinius A, Jansson L, Korsgren O (1995) Ultrastructural evidence for blood microvessels devoid of an endothelial cell lining in transplanted pancreatic islets. Am J Pathol 146:429 435

11. Lou J, Triponez F, Oberholzer J et al (1999) Expression of alpha-1 proteinase inhibitor in human islet microvascular endothelial cells. Diabetes 48:1773-1778

12. Lammert E, Gu G, McLaughlin M et al (2003) Role of VEGF$A$ in vascularization of pancreatic islets. Curr Biol 13:1070 1074

13. Esser S, Wolburg K, Wolburg H, Breier G, Kurzchalia T, Risau W (1998) Vascular endothelial growth factor induces endothelial fenestrations in vitro. J Cell Biol 140:947-959

14. Cepinskas G, Noseworthy R, Kvietys PR (1997) Transendothelial neutrophil migration. Role of neutrophil-derived proteases and relationship to transendothelial protein movement. Circ Res 81:618-626

15. Breit SN, Wakefield D, Robinson JP, Luckhurst E, Clark P, Penny R (1985) The role of alpha 1-antitrypsin deficiency in the pathogenesis of immune disorders. Clin Immunol Immunopathol 35:363-380

16. Lammert E, Cleaver O, Melton D (2001) Induction of pancreatic differentiation by signals from blood vessels. Science 294:564-567

17. Sakamoto C, Goldfine ID, Roach E, Williams JA (1985) Localization of saturable CCK binding sites in rat pancreatic islets by light and electron microscope autoradiography. Diabetes 34:390-394

18. Treutelaar MK, Skidmore JM, Dias-Leme CL et al (2003) Nestin-lineage cells contribute to the microvasculature but not endocrine cells of the islet. Diabetes 52:2503-2512

19. Bonner-Weir S (1994) Regulation of pancreatic beta-cell mass in vivo. Recent Prog Horm Res 49:91-104

20. Duvillie B, Currie C, Chrones T et al (2002) Increased islet cell proliferation, decreased apoptosis, and greater vascularization leading to beta-cell hyperplasia in mutant mice lacking insulin. Endocrinology 143:1530-1537

21. Kestila M, Lenkkeri U, Mannikko M et al (1998) Positionally cloned gene for a novel glomerular protein-nephrin - is mutated in congenital nephrotic syndrome. Mol Cell 1:575-582

22. Holzman LB, St John PL, Kovari IA, Verma R, Holthofer H, Abrahamson DR (1999) Nephrin localizes to the slit pore of the glomerular epithelial cell. Kidney Int 56:1481-1491

23. Ruotsalainen V, Ljungberg P, Wartiovaara J et al (1999) Nephrin is specifically located at the slit diaphragm of glomerular podocytes. Proc Natl Acad Sci U S A 96:7962-7967

24. Tryggvason K, Wartiovaara J (2001) Molecular basis of glomerular permselectivity. Curr Opin Nephrol Hypertens 10:543-549 
25. Putaala H, Soininen R, Kilpelainen P, Wartiovaara J, Tryggvason $\mathrm{K}$ (2001) The murine nephrin gene is specifically expressed in kidney, brain and pancreas: inactivation of the gene leads to massive proteinuria and neonatal death. Hum Mol Genet 10: $1-8$

26. Palmen T, Ahola H, Palgi J et al (2001) Nephrin is expressed in the pancreatic beta cells. Diabetologia 44:1274-1280

27. Kuusniemi A-M, Kestilä M, Patrakka J et al (2004) Tissue expression of nephrin in human and pig. Pediatr Res 55:774781

28. Huang GC, Zhao M, Jones P et al (2004) The development of new density gradient media for purifying human islets and isletquality assessments. Transplantation 77:143-145

29. Camussi G, Aglietta M, Malavasi F et al (1983) The release of platelet activating factor from human endothelial cell in culture. J Immunol 131:2397-2403

30. Xu Y, Swerlick RA, Sepp N, Bosse D, Ades EW, Lawley TJ (1994) Characterization of expression and modulation of cell adhesion molecules on an immortalized human dermal microvascular endothelial cell line (HMEC-1). J Invest Dermatol 102:833-837

31. Bussolati B, Deambrosis I, Russo S, Deregibus MC, Camussi G (2003) Altered angiogenesis and survival in human tumorderived endothelial cells. FASEB J 17:1159-1161

32. Zanone MM, Favaro E, Conaldi PG et al (2003) Persistent infection of human microvascular endothelial cells by coxsackie $B$ viruses induces increased expression of adhesion molecules. J Immunol 171:438-446

33. Doublier S, Salvidio G, Lupia E et al (2003) Nephrin expression is reduced in human diabetic nephropathy: evidence for a distinct role for glycated albumin and angiotensin II. Diabetes 52:1023-1030

34. Ruotsalainen V, Reponen P, Khoshnoodi J, Kilpelainen P, Tryggvason K (2004) Monoclonal antibodies to human nephrin. Hybrid Hybridomics 23:55-63
35. Doublier S, Ruotsalainen V, Salvidio G et al (2001) Nephrin redistribution on podocytes is a potential mechanism for proteinuria in patients with primary acquired nephrotic syndrome. Am J Pathol 158:1723-1731

36. Beltcheva O, Kontusaari S, Fetissov S et al (2003) Alternatively used promoters and distinct elements direct tissuespecific expression of nephrin. J Am Soc Nephrol 14:352-358

37. Liu L, Aya K, Tanaka H, Shimizu J, Ito S, Seino Y (2001) Nephrin is an important component of the barrier system in the testis. Acta Med Okayama 55:161-165

38. Holthofer H, Ahola H, Solin ML et al (1999) Nephrin localizes at the podocyte filtration slit area and is characteristically spliced in the human kidney. Am J Pathol 155:1681-1687

39. Lenkkeri U, Mannikko M, McCready P et al (1999) Structure of the gene for congenital nephrotic syndrome of the Finnish type (NPHS1) and characterization of mutations. Am J Hum Genet 64:51-61

40. Huber TB, Kottgen M, Schilling B, Walz G, Benzing T (2001) Interaction with podocin facilitates nephrin signaling. J Biol Chem 276:41543-41546

41. Karin M, Liu Z, Zandi E (1997) AP-1 function and regulation. Curr Opin Cell Biol 9:240-246

42. Huber TB, Hartleben B, Kim J et al (2003) Nephrin and CD2AP associate with phosphoinositide 3-OH kinase and stimulate AKT-dependent signalling. Mol Cell Biol 23:49174928

43. Lahdenpera J, Kilpelainen P, Liu XL et al (2003) Clusteringinduced tyrosine phosphorylation of nephrin by Src family kinases. Kidney Int 64:404-413

44. Verma R, Wharram B, Kovari I et al (2003) Fyn binds to and phosphorylates the kidney slit diaphragm component Nephrin. J Biol Chem 278:20716-20723

45. Sugimoto H, Hamano Y, Charytan D et al (2003) Neutralization of circulating vascular endothelial growth factor (VEGF) by anti-VEGF antibodies and soluble VEGF receptor 1 (sFlt-1) induces proteinuria. J Biol Chem 278:12605-12608 